\title{
Myxofibrosarcoma of the Thyroid: Second Case in Africa
}

\author{
Asmaa Salama $^{1 *}$, Nesreen Hafez ${ }^{1}$, Eman Abu-Sinna ${ }^{1}$, Ashraf Hassouna ${ }^{2}$ and Ayman A. Amin ${ }^{3}$ \\ ${ }^{1}$ Department of Pathology, National Cancer Institute, Cairo University, Egypt \\ ${ }^{2}$ Department of Radiation oncology, National Cancer Institute, Cairo University, Egypt \\ ${ }^{3}$ Department of Surgical Oncology, National Cancer Institute, Cairo University, Egypt \\ *Corresponding author: Asmaa Salama, Department of Pathology, National Cancer Institute, Cairo University, Egypt, Tel: 0201097804478; E-mail: \\ Almadina.salama@gmail.com
}

Rec date: Jun 06, 2014, Acc date: Jun 28, 2014, Pub date: Jun 30, 2014

Copyright: (C) 2014 Salama A, et al. This is an open-access article distributed under the terms of the Creative Commons Attribution License, which permits unrestricted use, distribution, and reproduction in any medium, provided the original author and source are credited.

\begin{abstract}
Myxofibrosarcoma is a common sarcoma in the extremities, but is rare in the head and neck region. Here, we report a case of 76 year old female patient in whom myxofibrosarcoma generated from the thyroid. The tumor was characterized by spindle cell proliferation with low to moderate cellular density in myxoid stroma. Immunohistochemically, the tumor cells showed positive reactivity for vimentin and actin, but negative staining for S-100, CK and desmin. Tumor cells showed low proliferative activity as demonstrates by low Ki-67 labelling index $(5 \%)$. The tumor was diagnosed as a low-grade myxofibrosarcoma. Despite the suboptimal general conditions of the patient, yet, surgery was the sole treatment of her and was successfully done. Adjuvant radiotherapy was indicated due to close circumferential margin. Myxofibrosarcoma is a very rare tumor in the head and neck region, and morphology beside immunohistochemistry is powerful tools to establish the diagnosis. Surgery is the main line of treatment followed by adjuvant radiotherapy to improve patient's survival.
\end{abstract}

Keywords: Myxofibrosarcoma; Thyroid

\section{Background}

The majority of malignant thyroid neoplasms are carcinomas (papillary, follicular and medullary), followed by non-Hodgkin lymphoma (NHL), but sarcomas are very rare with few countable cases all over the world. Myxofibrosarcoma (MFS) is malignant fibroblastic tumor with variable myxoid stroma, cellular pleomorphism and curvilinear vascular pattern. It usually affects elderly patients with male predominance. The majority of these tumors arise in limbs but rarely in the trunk, head and neck, hands, and feet [1]. Few cases were reported in larynx [2], esophagus [3], sphenoid sinus [4,5], mandible [6], maxillary sinus [7], parotid $[8,9]$, orbit $[10,11]$ and infratemporal space [12]. To our knowledge, only one case was reported in the hypopharynx [13] and another case involved the thyroid [14]. This work is conducted to report an additional MFS case arising in the thyroid.

\section{Case Presentation}

A 76 year-old female presented to the Surgical Oncology Clinic, National Cancer Institute, Cairo University in September 2013. She complained of rapidly enlarging left lower neck mass and dyspnea. High resolution ultrasonography of the thyroid gland showed bilateral ill defined heterogeneous thyroid nodules, the Lt. measures $7.1 \times 4.5 \mathrm{~cm}$ while the Rt. measures $1.4 \times 1.6 \mathrm{~cm}$. It displaces the carotid sheath posteriorly. A neck computed tomography revealed a large solid mass measures about $7 \times 6 \times 5 \mathrm{~cm}$ replacing the Lt. lobe. It shows heterogeneous enhancement with cystic degeneration, no matrix calcification, the lesion extends superiorly in the pharyngeal space reaching the lower part of the hypopharynx displacing thyroid and cricoid cartilages to the Rt. side, inferiorly to the retrosternal region, posteromedially displacing and compressing the trachea and oesophagus alongside with compressing Lt. longus colli muscle with no evidence of intraspinal extension or vertebral erosion, anterolateral displacing Lt. common carotid artery and internal jugular vein with displacing Lt. sternocleidomastoid muscle anteriorly (Figure 1). Rt. thyroid lobe shows relatively well defined heterogeneous nodule measuring $1.6 \times 1.4 \mathrm{~cm}$. Thyroid function test was within normal limits. Fine needle aspiration cytology (FNAC) was performed by using 23gauge disposable needles fitted to $5 \mathrm{ml}$ plastic syringes after correct positioning of the patient and cleaning of skin with antiseptic solution. Two passes of the thyroid nodule were performed. The aspirated smears were immediately fixed in 95\% ethyl alcohol at room temperature for about 30 minutes and were stained with modified Papanicolou stain. Microscopic examination revealed spindle cell proliferation of moderate cellularity and occasional blood vessel fragments embedded in myxoid background. The cells had moderately atypical spindle-shaped nuclei with moderate amount of ill-defined cytoplasm. Few scattered large bizarre cells with eccentric hyperchromatic nuclei and abundant cytoplasm were also detected. The cytological diagnosis was "anaplastic thyroid carcinoma, recommended for correlation with clinico-radiological data" (Figure 2).

The old patient had history of chronic valvular heart disease. For fear of peri-operative complications, internal medicine and nuclear medicine consultation were done but there was no role for chemotherapy or radioactive iodine therapy. Radiotherapy was contraindicated to avoid worsening of dyspnea. The hemodynamic stability of patient was hardly adjusted and life-saving neck exploration was performed for either possibility of dissection or tracheotomy, and ultimately, total thyroidectomy was performed on 23rd of October 2013. 
Page 2 of 4
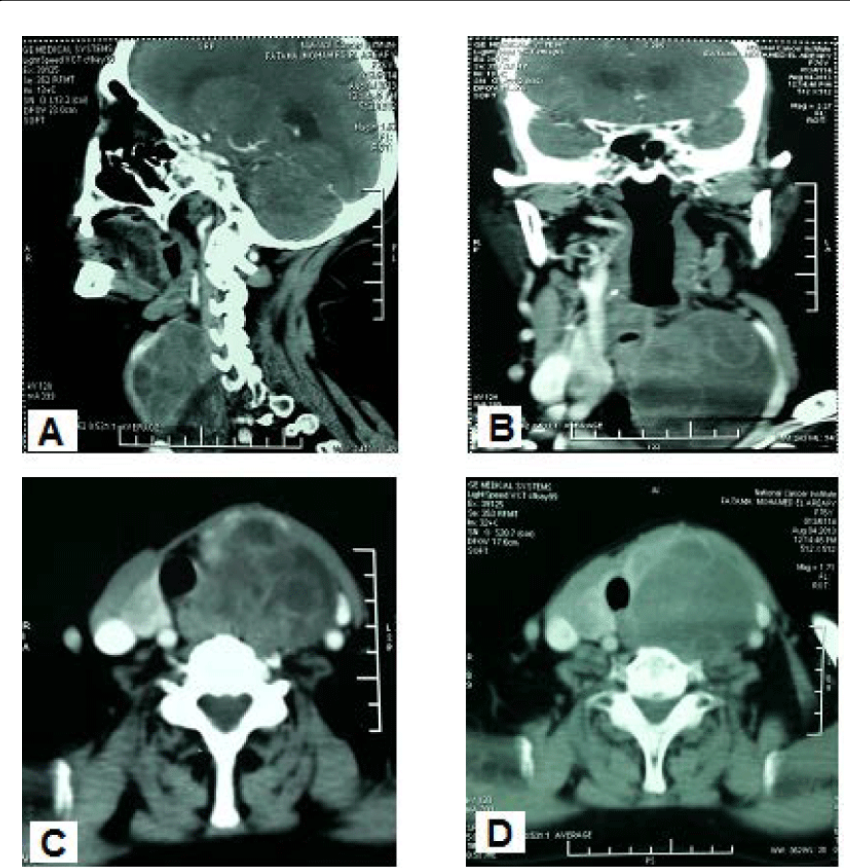

Figure 1: CT neck with contrast (A, sagittal; B, coronal; and C \&D axial views) shows large mixed solid cystic lesion in the left thyroid lobe with heterogeneous enhancement with cystic degradation, retrosternal extension, displacing and compressing the trachea, and displacing the carotid sheath posteriorly.

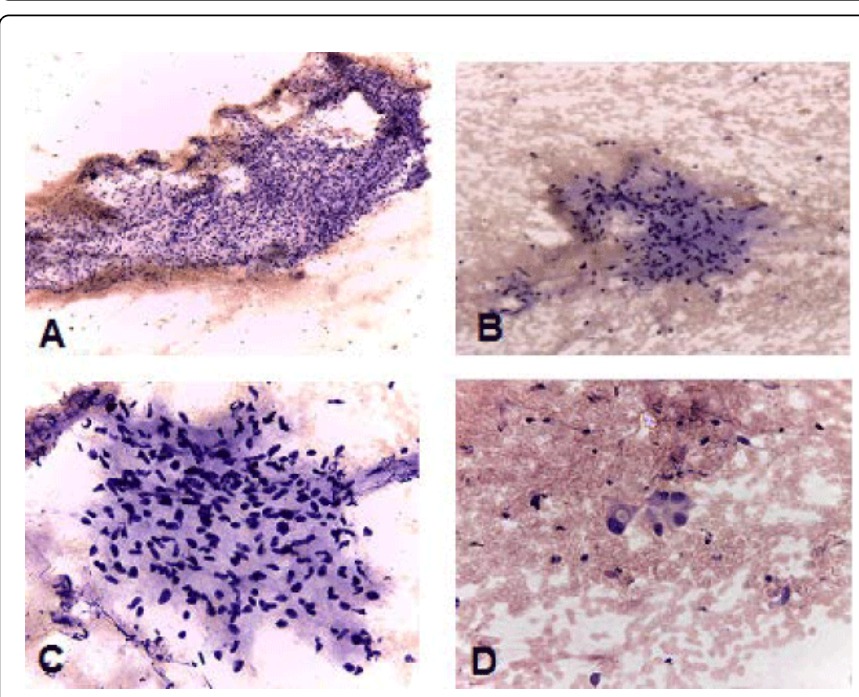

Figure 2: A, moderately cellular smear revealed spindle cell proliferation in myxoid stroma (Papanicolaou stain $\mathrm{x} \mathrm{100);} \mathrm{B,}$ spindle cells and blood vessel fragment embedded in myxoid background (Papanicolaou stain x 100); C, moderately atypical spindle cells with oval to spindle nuclei in myxoid stroma (Papanicolaou stain $\mathrm{x}$ 400); D, scattered cells with eccentric hyperchromatic nuclei and abundant cytoplasm (Papanicolaou stain $\mathrm{x}$ 400).
Gross examination revealed total thyroidectomy specimen; Lt. lobe measured $7 \times 6 \times 5 \mathrm{~cm}$, Rt. lobe measured $4 \times 2.5 \times 2 \mathrm{~cm}$ and isthmus measured $2 \times 1 \mathrm{~cm}$. The outer surface was lobulated with intact capsule. Serial sections revealed an ill-defined non-capsulated greyish white firm mass, infiltrated most of the Lt. Lobe and extended to the isthmus and part of the Rt. lobe. Remaining thyroid tissue was soft and brown.

Microscopic examination revealed a vague nodular pattern with illdefined infiltrative margins. The tumor was composed of alternating hypocellular and hypercellular areas, populated by plump noncohesive spindle cells with ill-defined eosinophilic cytoplasm and atypical hyperchromatic nuclei. Few scattered mitotic figure were detected. The stroma was myxoid with characteristic elongated curvilinear thin walled blood vessels and perivascular aggregates of lymphocytes. Tumor infiltrated the Lt. Lobe, isthmus and insinuated between thyroid follicles in the Rt. lobe. Tumor was close to the circumferential margins. Tumor cells stained positively for vimentin and actin. CK, S100 and desmin were negative. Ki-67 labeling index was $5 \%$ denoting low proliferative activity (Figure 3 ).

The huge size of the mass and the close surgical margin were the indications for postoperative adjuvant radiotherapy. It was planned to receive $66 \mathrm{~Gy} / 33$ fractions localized to the tumor bed and she is still under radiotherapy.

\section{Discussion}

Myxofibrosarcoma is one of the most common sarcomas in elderly patients with a slight male predominance. The majority of these tumors arise in the limbs including the limb girdles, whereas they are seen only rarely on the trunk, in the head and neck area, and on the hands and feet. Notably, about two-thirds of cases develop in dermis/ subcutaneous tissue, with the remainder occurring in the underlying fascia and skeletal muscles [1].

Head and neck localization of Myxofibrosarcoma is extremely rare and up to our knowledge, this is the second case of thyroid myxofibrosarcoma in Africa after the case diagnosed from Côted'Ivoire14. Only 20 cases have been described in the head and neck [3,5-24] so far, our case being the second one in the thyroid.

The initial diagnosis of our case was anaplastic thyroid carcinoma based on FNAC which revealed proliferating atypical spindle cells within myxoid background and scattered blood vessels. This is the most common diagnosis of large mass in old patient. Upon histopathologic examination, presence of nodular growth pattern populated by proliferating malignant spindle cells with moderate pleomorphism and lying within myxoid stroma with varying degree of cellularity and harbouring the characteristic curvilinear blood vessels raise the possibility of MFS. Immunohistochemistry confirmed this diagnosis by positive reaction to vimentin and negative reaction to $\mathrm{CK}$ as well as low proliferative activity as estimated by both low mitotic count and low Ki-67 labelling index (5\%), hence, the diagnosis of MFS was settled.

Complete tumor resection with adequate resection margin remains the mainstay for treatment of MFS. The radiotherapy is applied only for recurrent, unresectable lesions or tumors with close/positive resection margins, to suppress local recurrence and the risk of histologic progression, especially for low-grade MFS. The value of chemotherapy in MFS is still a debatable issue [5]. Low-grade MFS is considered to have low grade malignancy, and rarely shows distant metastasis, implying a good short-term prognosis. The overall 5-year 
Page 3 of 4

survival rate is $60 \%$ to $70 \%$ [15]. However, the local recurrence rate of the low-grade type is as high (50\% to $60 \%)$ as that of the high-grade type. It has continuity from low- to high-grade subdivision, showing low-grade areas in high-grade lesions, and a histologic progression of low to high-grade tumors in recurrences, hence acquiring metastatic potential. Therefore, these patients should be placed under long-term follow-up.
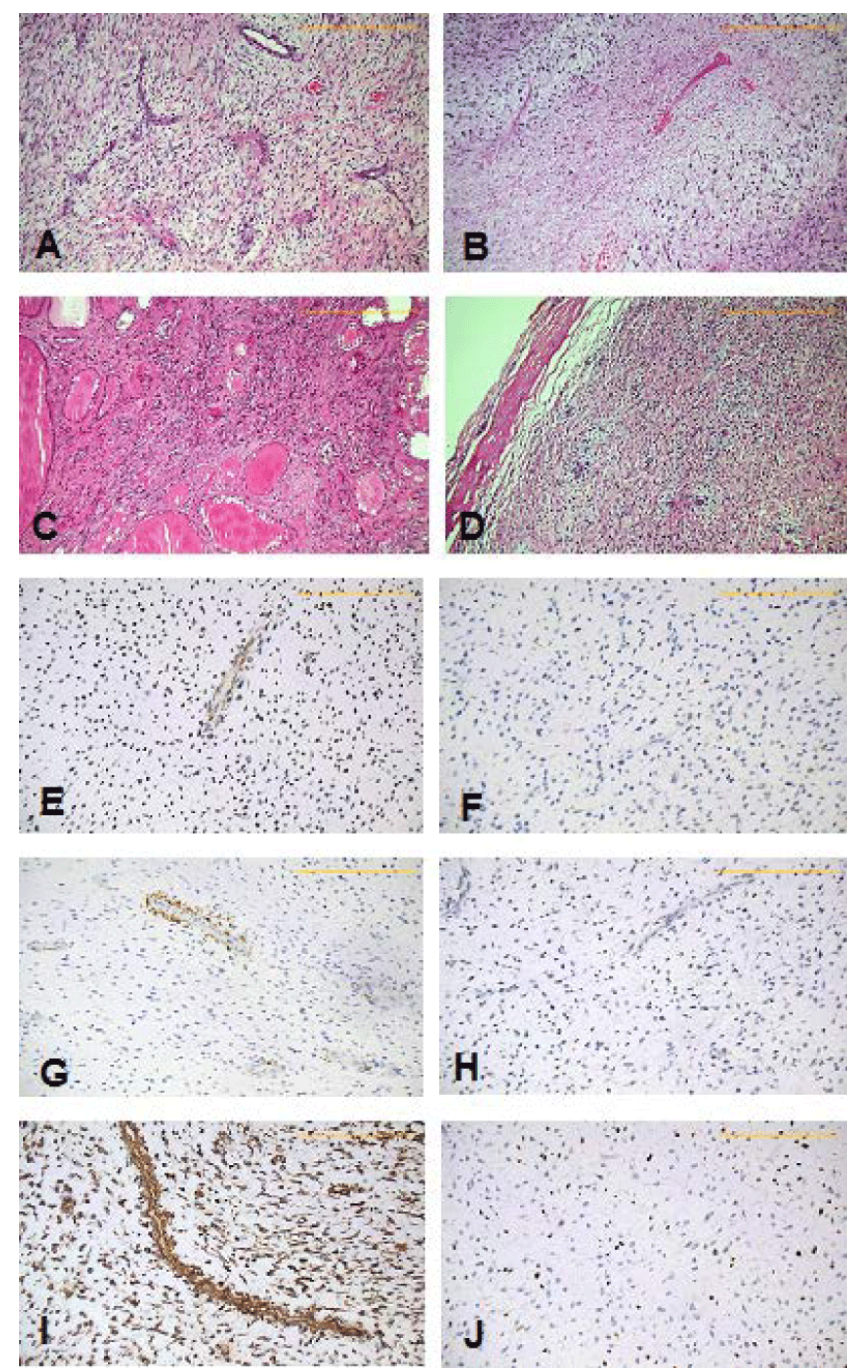

Figure 3: Histopathological examination revealed sheet of proliferating spindle cells within myxoid stroma with characteristic curvilinear blood vessels (A) (Hx\&E, x100), with focal necrosis (B) (Hx\&E, x100). Tumor cells are seen infiltrating in between thyroid follicles (C) (Hx\&E, x200) with close circumferential margin (D) (Hx\&E, x100). Tumor cells stained positively for actin (E) and vimentin (I), but negatively to CK (F), desmin (G) and S100 (H). $\mathrm{Ki}-67$ labelling index is about $5 \%(\mathrm{~J})$ (E-J, Immunoperoxidase, $\mathrm{x} 200)$.

\section{Conclusion}

Myxofibrosarcoma is a rare malignancy in the head and neck region and this is the second case in Africa at the thyroid. Despite the suboptimal general conditions of the patient, yet, surgery was the sole treatment of her and was successfully done. Immunohistochemistry remains the cornerstone of diagnosis after histopathological examination of abundant sampled sections of the tumor. Adjuvant radiotherapy is very important in the treatment of head and neck sarcomas due to inability to obtain adequate surgical clearance and to improve the survival of those patients.

\section{References}

1. Mentzel T, van den Berg E, Molenaar WM (2002) Fibroblastic/ Myofibroblastic Tumors In: Pathology and Genetics of Tumors of Soft Tissue and Bone, Fletcher C, Unni K and Mertens F (edn), IARC Press, Lyon, France.

2. Prasad I, Sharan R (1981) Myxofibrosarcoma of larynx. Indian J Otolaryngol HeadNeck Surg 33: 71-71.

3. Song HK, Miller JI (2002) Primary myxofibrosarcoma of the esophagus. J Thorac Cardiovasc Surg 124: 196-197.

4. Enomoto K, Inohara H, Hamada K, Tamura M, Tomita Y, et al. (2008) FDG PET imaging of myxofibrosarcoma on the sphenoid sinus. Clin Nucl Med 33: 421-422.

5. Lam PK, Trendell-Smith N, Li JH, Fan YW, Yuen AP (2002) Myxofibrosarcoma of the sphenoid sinus. J Laryngol Otol 116: 464-466.

6. Zouloumis L, Ntomouchtsis A, Lazaridis N (2010) Giant myxofibrosarcoma of the mandible. Balkan Journal of Stomatology 14: $41-44$.

7. Norval EJ, Raubenheimer EJ (2011) Myxofibrosarcoma arising in the maxillary sinus: a case report with a review of the ultrastructural findings and differential diagnoses. J Maxillofac Oral Surg 10: 334-339.

8. Li X, Chen X, Shi ZH, Chen Y, Ye J, et al. (2010) Primary myxofibrosarcoma of the parotid: case report. BMC Cancer 10: 246.

9. Srinivasan B, Ethunandan M, Hussain K, Ilankovan V (2011) Epitheloid myxofibrosarcoma of the parotid gland. Case Rep Pathol 2011: 641621.

10. Zhang Q, Wojno TH, Yaffe BM, Grossniklaus HE (2010) Myxofibrosarcoma of the orbit: a clinicopathologic case report. Ophthal Plast Reconstr Surg 26: 129-131.

11. Imai Y, Sugawara Y, Okazaki M, Harii K (2000) Low grade myxofibrosarcoma in the orbit: a case report. Japanese J Plastic Reconstructive Surg 43: 401-409.

12. Krishnamurthy A, Vaidhyanathan A, Majhi U (2011) Myxofibrosarcoma of the infratemporal space. J Cancer Res Ther 7: 185-188.

13. Nishimura G, Sano D, Hanashi M, Yamanaka S, Tanigaki Y, et al. (2006) Myxofibrosarcoma of the hypopharynx. Auris Nasus Larynx 33: 93-96.

14. Kouassi YM, Tanon-Anoh MJ, Doukouré B, Assouan C, Buraïma F, et al. (2010) [Thyroid localization of myxofibrosarcoma: first case in Africa]. Med Trop (Mars) 70: 70-72.

15. Nishio J, Iwasaki H, Nabeshima K, Naito M (2011) Cytogenetics and molecular genetics of myxoid soft-tissue sarcomas. Genet Res Int 2011: 497148.

16. Blitzer A, Lawson W, Zak FG, Biller HF, Som ML (1981) Clinicalpathological determinants in prognosis of fibrous histiocytomas of head and neck. Laryngoscope 91: 2053-2070.

17. Pomerantz JM, Sanfacon DG, Dougherty TP, Hanson S (1982) Myxofibrosarcoma of the maxillary sinus. Del Med J 54: 147-152.

18. Barnes L, Kanbour A (1988) Malignant fibrous histiocytoma of the head and neck. A report of 12 cases. Arch Otolaryngol Head Neck Surg 114: 1149-1156.

19. Iguchi Y, Takahashi H, Yao K, Nakayama M, Nagai H, et al. (2002) Malignant fibrous histiocytoma of the nasal cavity and paranasal sinuses: review of the last 30 years. Acta Otolaryngol Suppl : 75-78.

20. Udaka T, Yamamoto H, Shiomori T, Fujimura T, Suzuki H (2006) Myxofibrosarcoma of the neck. J Laryngol Otol 120: 872-874.

21. Enoz M and Suoglu Y (2007) Myxofibrosarcoma of the maxillary sinus. Internet J Head Neck Surg 1: 1-4. 
Citation: Salama A, Hafez N, Abu-Sinna E, Hassouna A, Amin AA (2014) Myxofibrosarcoma of the Thyroid: Second Case in Africa. J Cytol Histol 5: 257. doi:10.4172/2157-7099.1000257

Page 4 of 4

22. Gugatschka M, Beham A, Stammberger H, Schmid C, Friedrich G (2010) First case of a myxofibrosarcoma of the vocal folds: case report and review of the literature. J Voice 24: 374-376.

23. Nakahara S, Uemura H, Kurita T, Suzuki M, Fujii T, et al. (2012) A case of myxofibrosarcoma of the maxilla with difficulty in preoperative diagnosis. Int J Clin Oncol 17: 390-394.
24. Qiubei Z, Cheng L, Yaping X, Shunzhang L, Jingping F (2012) Myxofibrosarcoma of the sinus piriformis: case report and literature review. World J Surg Oncol 10: 245. 